\title{
First principle calculation of structure and lattice dynamics of $\mathrm{Lu}_{2} \mathrm{Si}_{2} \mathrm{O}_{7}$
}

\author{
D.V. Nazipov ${ }^{1, *}$, and A.E. Nikiforov ${ }^{1}$ \\ ${ }^{1}$ Ural Federal University, 620002 Ekaterinburg, Russia
}

\begin{abstract}
Ab initio calculations of crystal structure and Raman spectra has been performed for single crystal of lutetium pyrosilicate $\mathrm{Lu}_{2} \mathrm{Si}_{2} \mathrm{O}_{7}$. The types of fundamental vibrations, their frequencies and intensities in the Raman spectrum has been obtained for two polarizations. Calculations were made in the framework of density functional theory (DFT) with hybrid functionals. The isotopic substitution was calculated for all inequivalent ions in cell. The results in a good agreement with experimental data.
\end{abstract}

In this work we present ab initio calculations of the crystal structure and phonon spectra of the lutetium pyrosilicate. Lutetium pyrosilicate (LPS) is a good optical matrix [1-3]. Doped with rare-earth ions LPS actively studied as a perspective laser material. LPS crystal have a low symmetrical monoclinic crystal structure, space group C $2 / \mathrm{m}$. Low symmetrical crystals are hard for investigation from experimental point of view. In the present study, crystal structure parameters and vibrational spectra obtained in good agreement with experiment.

Investigations performed in molecular orbitals LCAO approximation, using DFT method with hybrid functional WC1LYP in program package CRYSTAL14 [4]. Ions was described by full-electron basis sets (for $\mathrm{Si}^{3+}, \mathrm{O}^{2-}$ ) and by pseudopotential for $\mathrm{Bi}^{3+}$.

In the work [5], devoted to a detailed study of the vibrational Raman spectrum of lutetium pyrosilicate, first identified the complete set of lattice vibrations of LPS and pyroion $\left[\mathrm{Si}_{2} \mathrm{O}_{7}\right]^{6-}$.

Challenging task from experimental point of view was identifying close lying lines such as № 6, 7 and № 14, 15. Calculations are performed for an ideal crystal and without the influence of the birefringence effect which makes difficult to separate $\mathrm{A}_{\mathrm{g}}$ and $\mathrm{B}_{\mathrm{g}}$ modes in the spectrum. Also hard to identify low intensity modes. In the work [5] was identified № 3 mode, which was absent in the work [6]. According to our results the № 3 mode has a 300 times smaller intensity than most intense mode № 8. Obtained spectra have been analyzed using isotopic shift method and ions involved in vibrations have been identified. According to our data, oxygen $\mathrm{O} 1$, which forms a bridge bound $\mathrm{Si}-\mathrm{O} 1-\mathrm{Si}$, involved only in highfrequent $\mathrm{A}_{\mathrm{g}}=927 \mathrm{~cm}^{-1}$ mode. Low frequency modes correspond to vibrations of $\mathrm{Lu}$ heavy ion. Ions of Si have biggest activity predominantly in modes with frequency more than $490 \mathrm{~cm}^{-1}$. Summing up, the identification of full set of Raman active phonons, which obtained in [5] for the first time, is confirmed by first principle DFT calculations and spectrum is analyzed by the isotopic substitution method.

\footnotetext{
* Corresponding author: qwear0@gmail.com
} 

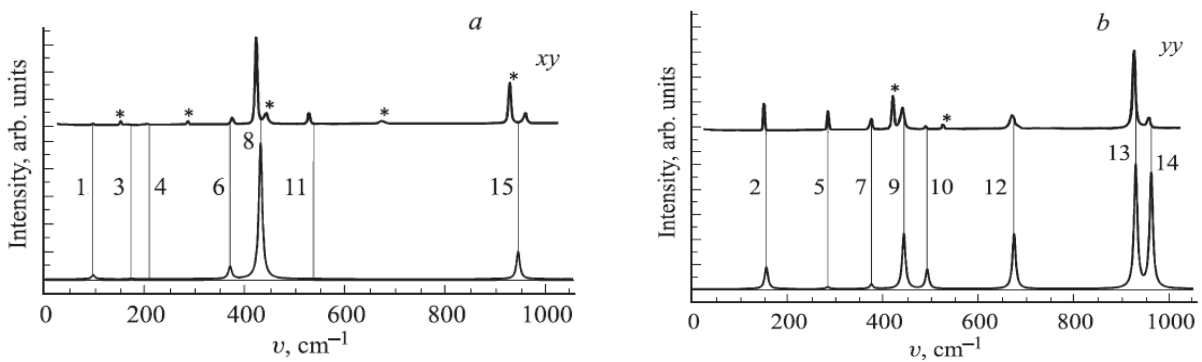

Fig. 1. Comparison of experimental [5] (top) and calculated in this work (bottom) Raman spectra, in xy (a) and yy (b) polarizations.

Table 1. Frequencies of phonon modes that are active in the Raman spectrum of $\mathrm{Lu}_{2} \mathrm{Si}_{2} \mathrm{O}_{7}$ and ions involved in vibrations, determined by the method of isotopic substitution. (Experimental data are given in brackets [5])

\begin{tabular}{c|c|c|c}
\hline № & $\begin{array}{c}\text { Irreducible } \\
\text { representation }\end{array}$ & Freqency, $\mathrm{cm}^{-1}$ & Involved ions \\
\hline 1 & $\mathrm{~B}_{\mathrm{g}}$ & $95(95)$ & $\mathrm{Lu}$ \\
2 & $\mathrm{~A}_{\mathrm{g}}$ & $157(150)$ & $\mathrm{Lu}$ \\
3 & $\mathrm{~B}_{\mathrm{g}}$ & $171(163)$ & $\mathrm{Lu}$ \\
4 & $\mathrm{~B}_{\mathrm{g}}$ & $207(204)$ & $\mathrm{O} 3$ \\
5 & $\mathrm{Ag}_{\mathrm{g}}$ & $385(285)$ & $\mathrm{O} 2$ \\
6 & $\mathrm{~B}_{\mathrm{g}}$ & $367(373)$ & $\mathrm{O} 2$ \\
7 & $\mathrm{~A}_{\mathrm{g}}$ & $476(376)$ & $\mathrm{O} 3$ \\
8 & $\mathrm{~B}_{\mathrm{g}}$ & $428(422)$ & $\mathrm{O} 3$ \\
9 & $\mathrm{Ag}_{\mathrm{g}}$ & $444(441)$ & $\mathrm{Si}, \mathrm{O} 3$ \\
10 & $\mathrm{Ag}_{\mathrm{g}}$ & $523(490)$ & $\mathrm{O} 2$ \\
11 & $\mathrm{~B}_{\mathrm{g}}$ & $675(672)$ & $\mathrm{Si}$ \\
12 & $\mathrm{Ag}_{\mathrm{g}}$ & $931(927)$ & $\mathrm{Si}, \mathrm{O} 1, \mathrm{O} 3$ \\
13 & $\mathrm{~A}_{\mathrm{g}}$ & $963(955)$ & $\mathrm{Si}, \mathrm{O} 2$ \\
14 & $\mathrm{~A}_{\mathrm{g}}$ & $941(959)$ & $\mathrm{Si}, \mathrm{O} 3$ \\
15 & $\mathrm{~B}_{\mathrm{g}}$ &
\end{tabular}

The full set of modes of the phonon spectrum of $\mathrm{Lu}_{2} \mathrm{Si}_{2} \mathrm{O}_{7}$ and their frequencies and types have been calculated (table 1). Intensities of modes, active in the Raman spectra, have been obtained for two polarizations xy and yy (fig. 1).

This work was supported by Ministry of Education and Science of the Russian Federation (project № 3.571.2014/K), Government of Russian Federation (Contract № 02.A03.21.0006, decree № 211) and Russian Foundation for Basic Research (project № 16-33-00437-mol_a.).

\section{References}

1. D. Pauwels et al., IEEE Transactions on Nuclear Science 47, 1787 (2000)

2. H. Yang, G. Lui, Q. Lu, Q. Wei, J. Zhuang, Q. Liu, Appl. Surf. Sci. 301, 323 (2014)

3. E. Dell'Orto, M. Fasoli, G. Ren, A. Vedda, J. Phys. Chem. C 117, 20201 (2013)

4. http://www.crystal.unito.it

5. U.K. Voronko, A.A. Sobol, V.E. Shukshin, I.V. Gerasimov, Fizika tverdogo tela 57, 1398 (2015)

6. F. Bretheau-Raynal, J.P. Dalbiez, M. Drifford, B. Blanzat, J. Raman Spectr. 8, 39 (1979) 